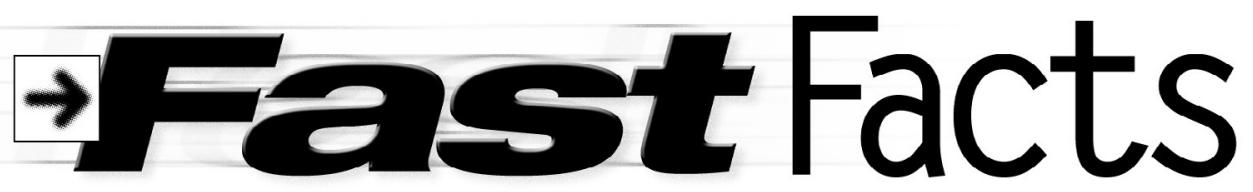

\title{
Zombie research
}

"Around one in 2,500 (scholarly journal articles) is retracted. Yet papers that do get retracted often have long afterlives." Twenty thousand withdrawn papers amassed by Retraction Watch "were cited in 95,000 articles after their retractions. In turn, these were cited in $1.65 \mathrm{~m}$ further papers."

"Zombie Research Haunts Academic Literature Long after Its Supposed Demise," The Economist, June 26, 2021, https:// www.economist.com/graphic-detail/2021/06/26/zombie-research-haunts-academic-literature-long-after-its-supposed -demise (retrieved September 28, 2021).

\section{Homeschooling}

"A growing number of Americans are teaching their children at home. According to the National Center for Education Statistics, the number of home-schooled students nearly doubled nationally from 850,000 in 1999 to 1,690,000 in 2016. The percentage of students who were home-schooled increased from 1.7 percent of all students to 3.3 percent of all students over the same time." According to the "Household Pulse Survey . . . the number of households with school-age children home-schooling doubled between spring 2020 and the start of the 2020-21 school year, rising from 5.4 percent to 11.1 percent." Joanne Brosh, "Home-Schooled Children Increasing in NC," The Well, September 22, 2021, https://thewell.unc. edu/2021/09/22/home-schooled-children-increasing-in-nc (retrieved September 22, 2021).

\section{Wikifunctions}

"Wikifunctions is a collaboratively edited catalog of computer functions that aims to allow the creation, modification, and reuse of source code. It is closely related to Abstract Wikipedia, an extension to Wikidata that aims to create a language-independent version of Wikipedia using its structured data. The Wikifunctions website is expected to launch in 2022 and will be the first new Wikimedia project to launch since 2012. A public demonstration system has been set up at https://notwikilambda.toolforge.org and was announced in October 2020."

Wikipedia contributors, "Wikifunctions," Wikipedia, The Free Encyclopedia, https://en.wikipedia.org/w/index.php?title $=$ Wikifunctions\&oldid=1046813716 (retrieved September 27, 2021).

\section{Internet freedom declines for 11th year in a row}

"An increase in network shutdowns, combined with a rise in disinformation campaigns, adds up to another decline in [I]nternet freedom in the [United States] and around the globe, according to Freedom House. It's the 11th consecutive year that the [I]nternet has been less free globally and the fifth straight yearly decline in the [United States], the group says in its annual report on the subject. The greatest declines in [I]nternet freedom over the last year took place in Myanmar, Belarus, and Uganda."

Ina Fried, "Internet Freedom Declines for 11th Year in a Row," Axios, September 21, 2021, https://www.axios.com/internet -freedom-declines-11th-year-81d2288b-b817-4945-8a35-e3189a8d504a.html (retrieved September 27, 2021).

\section{College student financial aid}

In 2017-18, 70 percent of all undergraduates received some type of financial aid (excluding private loans), and the average amount of aid received was $\$ 13,000$. Among states with samples that support reporting, undergraduates in Hawaii had the lowest rate of financial aid receipt (52 percent), and undergraduates in North Carolina (87 percent) and Louisiana (86 percent) had the highest rates of financial aid receipt.

Rachel Burns, et al. 2017-18 National Postsecondary Student Aid Study, Administrative Collection (NPSAS:18-AC): First Look at Student Financial Aid Estimates for 2017-18, (NCES 2021-476), September 2021, U.S. Department of Education. Washington, D.C.: National Center for Education Statistics, https://nces.ed.gov/pubsearch/pubsinfo.asp?pubid=2021476 (retrieved September 28, 2021).

Gary Pattillo is reference librarian at the University of North Carolina-Chapel Hill, e-mail: pattillo@email.unc.edu 